\title{
Yem Kaynaklı Borun Gökkuşağı Alabalığı (Oncorhynchus mykiss) Yă̆ Asidi Profiline Etkisi
}

\author{
Mustafa Öz ${ }^{*}$, Burak Evren İnanan ${ }^{2}$, Suat Dikel ${ }^{3}$ \\ 1* Aksaray Üniversitesi, Veteriner Fakültesi, Su Ürünleri ve Hastalıkları Bölümü, Aksaray, Türkiye, (ORCID: 0000-0001-5264-7103), ozmustafa@aksaray.edu.tr \\ ${ }^{2}$ Aksaray Üniversitesi, Veteriner Fakültesi, Su Ürünleri ve Hastalıkları Bölümü, Aksaray, Türkiye (ORCID: 0000-0002-2888-8457), burakinanan@aksaray.edu.tr \\ ${ }^{3}$ Çukurova Üniversitesi, Su Ürünleri Fakültesi, Yetiştiricilik Bölümü, Adana, Türkiye (ORCID: 0000-0002-5728-7052), dikel@cu.edu.tr
}

(İlk Geliş Tarihi 11 Ekim 2021 ve Kabul Tarihi 06 Aralık 2021)

(DOI: 10.31590/ejosat.1008443)

ATIF/REFERENCE: Öz, M., İnanan, B.E. \& Dikel, S. (2021). Yem Kaynaklı Borun Gökkuşağı Alabalığı (Oncorhynchus mykiss) Yağ Asidi Profiline Etkisi. Avrupa Bilim ve Teknoloji Dergisi, (31), 188-192.

$\ddot{O} \mathbf{z}$

$\mathrm{Bu}$ araştırmada su ürünleri yetiştiriciliği açısından çok önemli bir balık türü olan gökkuşağı alabalığ 1 yemine $\% 0, \% 0,01, \% 0,05, \%$ 0,10 ve $\% 0,20$ oranlarında bor ilave edilmiş ve 90 gün boyunca besleme yapılmıştır. Borik asit olarak ilave edilen borun, gökkuşağ 1 alabalığının yağ asidi profili üzerine etkileri araştırılmıştır. Araştırma başlangıcında yaklaşık 90 gram olan alabalıklar, 295 gram ağırlığa kadar beslenmiş ve hasat edilerek analize hazırlanmıştır. Balıkların filetoları çıkartıldıktan sonra balığın dorsal kısmında bulunan kaslar alınarak homojenize edilmiştir. Araştırmada balık kas dokusunun temel doymuş yağ asitlerini (DYA); laurik asit (C12:0), miristik asit (C14:0), palmitik asit (C16:0), margaric asit (C17:0), stearik asit (C18:0), arachidic acid (C20:0) ve lignoceric asit (C24:0) oluşturmaktadır. Gökkuşağı alabalığı kas dokusunun temel tekli doymamış yağ asitlerini (TDYA); myristoleic acid (C14:1), palmitoleic acid (C16:1), oleic acid (C18:1 n9), vaccenic acid (C18:1 n7), eicosenoic acid (C20:1) ve erucic acid (C22:1n9) oluşturmuştur. Balıketinden ekstrakte edilen balık yağının temel çoklu doymamış yă̆ asitlerini (ÇDYA) ise; linoleic acid (C18:2 n6), $\alpha$-linolenic acid (C18:3 n3), eicosadienoic acid (C20:2) arachidonic acid (C20:4 n6), eicosapentaenoic acid (C20:5 n3) ve docosahexaenoic acid C22:6 n3) oluşturmuştur. Araştırma sonucunda; en yüksek DYA ve TDYA oranı kontrol gurubunda görülürken en düşük DYA ve TDYA oranı en fazla bor uygulanan grupta görülmüştür. Balık yemlerine ilave edilen borun balıketinin ÇDYA oranlarında artış sağladığı görülmektedir. Yem kaynaklı borun yağ asidi profilini etkilediği sonucuna varılmıştır.

Anahtar Kelimeler: Gökkuşağı alabalığı, Yağ asidi, Bor.

\section{Effect of Dietary Boron on Fatty Acid Profile of Rainbow Trout (Oncorhynchus mykiss)}

\begin{abstract}
In this study, $0.00 \%, 0.01 \%, 0.05 \%, 0.10 \%$, and $0.20 \%$ of boron were added to rainbow trout feed as a very important fish species in aquaculture. After 90 days of the feeding trial, effect of boron on fatty acid profile of rainbow trout were determined. During the feeding trial average approximately $90 \mathrm{~g}$ of rainbow trouts were fed up to average approximately $295 \mathrm{~g}$, and then harvested. After the fish were filleted, their muscles in the dorsal part of the fish were removed and homogenized. Basic saturated fatty acids of fish muscle tissue were Lauric acid (C12:0), myristic acid (C14:0), palmitic acid (C16:0), Margaric acid (C17:0), Stearic acid (C18:0), Arachidic acid (C20:0) and Lignoceric acid (C24:0) while essential monounsaturated fatty acids of muscle tissue were Myristoleic acid (C14:1), Palmitoleic acid (C16:1), Oleic acid (C18: n9), Vaccenic acid (C18:1 n7), Eicosenoic acid (C20:1) and Erucic acid (C22:1n9). The basic polyunsaturated fatty acids of our fish meat were Linoleic acid (C18:2 n6), $\alpha$-Linolenic acid (C18:3 n3), eicosadienoic acid (C20:2) Arachidonic acid (C20:4 n6), Eicosapentaenoic acid (C20:5 n3) and Docosahexaenoic acid C22:6 n3). As a result, while the highest SFA and MUFA ratios were found in control group, the lowest SFA and MUFA ratios were observed in dietary boron groups. It has been observed that boron added to feeds increased the PUFA ratios of fish meat. It was concluded that feed-borne boron acid affected the fatty acid profile of fish meat.
\end{abstract}

Keywords: Rainbow trout, Fatty acid, Boron.

\footnotetext{
*Sorumlu Yazar: ozmustafa@aksaray.edu.tr
} 


\section{Giriş}

Balıklar ve diğer su ürünleri iyi bir protein kaynağı olmasının yanında önemli bir yağ kaynağıdır ve dokosaheksaenoik asit 22:6n-3), eikosapentaenoik asit (20:5n-3) ve alfa-linolenik asit gibi birçok çoklu doymamış omega $(\omega)$-3 yağ asidini içerir. $\omega-3$ PUFA'nın insan sağlı̆̆ koruyucu etkileri vardır (Uçak ve ark., 2019; Işık ve ark., 1999). Yapılan birçok araştırmada $\omega$-3 PUFA'nın meme, kolon, prostat, karaciğer ve pankreas kanseri dâhil olmak üzere çoğu kanser gelişimini baskılamada olumlu bir rol oynadığı bildirilmiştir. Yağlı balıklar EPA ve DHA'nın en önemli doğal kaynağı olduğundan, son yıllarda balık tüketiminde önemli talep artışları olmuştur (Uçak ve ark., 2019).

Doğal stokların azalması ve aşırı avcılık baskısı gibi sebeplerle avcılıktan gelen ürünün artırılmasındaki problemler, su ürünleri yetiştiricilik sektörünü daha da önemli bir konuma getirmiştir. Su ürünleri yetiştiriciliği bütün dünyada çok önemli bir meslek kolu haline gelmektedir. Dünya nüfusunun artması ve buna bağlı olarak protein ihtiyacının artması su ürünlerinin değerini daha da arttırmıştır. Özellikle şuan içinde bulunduğumuz küresel covid-19 salgını bağışıklık sistemini destekleyen su ürünleri gibi gıdaları çok daha önemli bir hale getirmektedir.

Türkiye gibi tamamen karnivor türlere dayalı bir yetiştiricilik modeline sahip olan ülkelerin su ürünleri sektöründeki büyümeyi sürdürülebilir halde tutabilmesi için ya yetiştirilen mevcut türleri gözden geçirmesi gerekmekte (Öz ve Üstüner, 2021) ya da mevcut türleri beslemede kullandıkları yem içeriklerini yenileyerek yemden yararlanmayı arttırmaları gerekmektedir.

Yetiştiricilik açısından yatırım maliyetlerinin yüksekliği, üretim sürecinin uzunluğu ve yetiştiricilik teknolojilerinin gereksinimlerinin yüksekliği birçok türün yetiştiriciliğini zor hale getirmekte hatta bu durumun gelecekte ciddi kisitlamalar yaratması beklenmektedir (Dikel, 2021).

Son yıllarda yapılan çalışmalarda araştırmacılar birçok maddenin balık yemlerinde yem katkı maddesi olarak kullanılabilirliğini araştırmışlardır (İnanan ve ark., 2021; Öz, M., 2018; Acar ve ark., 2021; Acar ve ark., 2019; Öz ve ark., 2018a). Borik asit te bu araştırmalara konu olan maddelerden biridir. Özellikle alabalık yemlerine ilave edilerek büyüme performansı (Öz ve ark., 2018b; Öz ve ark., 2017), balık etinin besinsel kompozisyonu (Öz ve ark., 2021) ve uzun süreli beslemelerde oluşturabileceği olumsuz etkileri araştırılmıştır (Öz ve ark., 2020a; Öz ve ark., 2020b). Fakat bir maddenin balık yemleri için yem katkı maddesi olarak önerilebilmesi için çok kapsamlı araştırmalara gereksinim duyulmaktadır. Sadece bir balık türünün bir boy grubu üzerine yapılan araştırmalar yeterli gelmeyebilir. Kesin bir değerlendirme yapabilmek için, farklı boy ve yaş grupları, farklı cinsiyet, farklı su sıcaklıkları, farklı mevsimler ve farklı sürelerde araştırmalar yapmak gerekir. Ayrıca elde edilen sonuçlar büyüme parametreleri açısından önemli olsa da balığın besin içeriği, et kalitesi üzerine olası etkilerinin belirlenmesi gerekmektedir.

$\mathrm{Bu}$ araştırmada, gökkuşağı alabalığının büyüme parametreleri üzerine olumlu etkileri olduğu bildirilen borik asit ilaveli yemle gökkuşağı alabalığı 90 gün beslenmiş ve balığın en faydalı kısımlarından olan yağ asitleri üzerine olan olası etkileri araştırılmıştır.

\section{Materyal ve Metot}

\subsection{Balıklar}

Bu çalışma Hayvan Deneyleri Yerel Etik Kurulun tarafindan onaylanmıştır (no. 3-2/2016, Adana). Besleme denemesi 90 gün boyunca sürmüştür ve beton havuzlar içerisine yerleştirilen $1 \mathrm{~m} \mathrm{x}$ $1 \mathrm{~m}$ çerçeve ölçüsü ve $1,5 \mathrm{~m}$ derinliğe sahip ağ kafeslerde 1 metrelik seviyesine kadar su doldurularak yapılmıştır. Araştırma başlangıcında ortalama yaklaşık 90 gram ağırlığa sahip olan gökkuşağı alabalığı araştırma sonunda ortalama yaklaşık 295 gram canlı ağırlığa ulaşmış ve hasat edilerek laboratuvara getirilmiştir.

\subsection{Deney Grupları ve Yemler}

Besleme denemesi öncesi balıklar 2 hafta boyunca adaptasyon süresi geçirmişler ve bu süre boyunca ticari alabalık yemi ile beslenmiştir (Skretting, Stavanger, Norveç). Bu ticari yemin besinsel değerleri Tablo 1 de gösterilmektedir. Adaptasyon sonras1, 4 farklı miktarda ( $\% 0,01, \% 0,05, \% 0,10$ ve $\% 0,20)$ bor içeren yemler hazırlanmış olup, bor ilave edilmeyen yem, kontrol gurubunun yemi olarak kullanılmıştır. Yemdeki bor oranları, borik asit (Sigma-Aldrich, Steinheim, Almanya) ile ayarlanmıştır. Bu çalışmadaki bor miktarlarına önceki çalışmalarda kullanılan bor miktarları dikkate alınarak karar verilmiştir (Öz ve ark., 2021; Öz ve ark., 2018; Ardo ve ark., 2007).

Tablo 1. Çalışmada kullanılan ticari alabalık yemine ait besinsel değerler.

\begin{tabular}{cc}
\hline İçerik & Miktar (\%) \\
\hline Ham Protein & 45 \\
Yağ & 20 \\
Ham selüloz & 2.0 \\
Ham Kül & 10 \\
Makro elementler & \\
Fosfor & 1.10 \\
Kalsiyum & 1.90 \\
Sodyum & 0.30 \\
\hline
\end{tabular}

\subsection{Yă̆ Asidi Analizi}

Yağlar temel olarak Folch ve ark., (1957) tarafindan belirlenen prosedüre göre ekstrakte edilmiştir. Yağların ekstraksiyonu sonrası, yağ asidi metil esterleri (YAME) Metcalfe ve Schmitz (1961) tarafından tanımlanan şekilde hazırlanmış ve Czesny ve Dabrowski 1998 tarafindan önerilen metoda uygun bir şekilde analiz edilmiştir. Metot kısaca şu şekilde özetlenebilir; elde edilen YAME, Agilent 6820 A model alev İyonizasyon Dedektörlü ve DB 23 kapiler kolonlu (60 m x $0.25 \mathrm{~mm}$ i.d. x 0.25 $\mu \mathrm{m})$ gaz kromotografi cihazı ile ayrılmıştır. Gaz kromotografisi çalışma şartları şu şekildedir; enjetör sıcaklığı 35 dakika $190{ }^{\circ} \mathrm{C}$ olup, sonrasında dakikada $30{ }^{\circ} \mathrm{C}$ hızla $220^{\circ} \mathrm{C}$ çıkartılmış ve bu sıcaklıkta 5 dakika tutulmuştur. Taşıyıcı gaz olarak hidrojen (2 $\mathrm{ml} /$ dak ve split oranı 30:1 olarak) kullanılmıştır. Her bir yağ asidi, yağ asitleri karışık standardından (Supelco 37 component FAME mix) elde edilen alıkonma zamanları ile karşılaştırılarak tayin edilmiştir. 


\section{4. İstatistiksel Analiz}

Elde edilen yağ asitlerinin gruplar arasındaki anlamlı farkların gösterilmesinde tek yönlü varyans analizi (ANOVA) ve sonrasında ikili karşılaştırmalar için post-hoc Tukey testi uygulanmıştır. İstatistiksel analizlerde SPSS 15.0 programı kullanılmıştır. Alınan sonuçlar, $\mathrm{P}<0,05$ önemlilik derecesine göre değerlendirilmiştir

Tablo 2. Farklı oranlarda bor ilave edilmiş yemlerle beslenen gökkuşă̆ı alabalı̆̆ (Oncorhynchus mykiss) ’nın yă̆ asidi profilleri.

\begin{tabular}{|c|c|c|c|c|c|}
\hline Yağ asitleri & $0.00 \%$ & $0.01 \%$ & $0.05 \%$ & $0.10 \%$ & $0.20 \%$ \\
\hline C12:0 & $2,52 \pm 0,06^{\mathrm{a}}$ & $1,81 \pm 0,02^{b}$ & $1,62 \pm 0,03^{\mathrm{c}}$ & $1,29 \pm 0,09^{\mathrm{d}}$ & $1,20 \pm 0,02^{\mathrm{d}}$ \\
\hline C14:0 & $2,71 \pm 0,02^{\mathrm{e}}$ & $2,99 \pm 0,03^{\mathrm{d}}$ & $3,21 \pm 0,04^{\mathrm{c}}$ & $3,46 \pm 0,05^{\mathrm{b}}$ & $3,64 \pm 0,06^{\mathrm{a}}$ \\
\hline C14:1 & $0,82 \pm 0,03^{\mathrm{a}}$ & $0,65 \pm 0,02^{\mathrm{b}}$ & $0,61 \pm 0,04^{\mathrm{b}}$ & $0,45 \pm 0,02^{\mathrm{c}}$ & $0,45 \pm 0,04^{\mathrm{c}}$ \\
\hline C15:0 & $1,02 \pm 0,03^{\mathrm{d}}$ & $1,41 \pm 0,05^{\mathrm{c}}$ & $1,55 \pm 0,07^{\mathrm{b}}$ & $1,89 \pm 0,02^{\mathrm{a}}$ & $1,98 \pm 0,03^{\mathrm{a}}$ \\
\hline C16:0 & $11,89 \pm 0,23^{\mathrm{a}}$ & $10,25 \pm 0,38^{\mathrm{b}}$ & $8,98 \pm 0,08^{\mathrm{c}}$ & $8,08 \pm 0,03^{\mathrm{d}}$ & $7,50 \pm 0,23^{\mathrm{d}}$ \\
\hline C16:1 & $0,52 \pm 0,05^{\mathrm{a}}$ & $0,38 \pm 0,01^{\mathrm{b}}$ & $0,34 \pm 0,01^{\mathrm{b}}$ & $0,32 \pm 0,02^{\mathrm{b}}$ & $0,25 \pm 0,02^{\mathrm{c}}$ \\
\hline C17:0 & $1,05 \pm 0,02^{\mathrm{a}}$ & $0,90 \pm 0,03^{\mathrm{b}}$ & $0,63 \pm 0,03^{\mathrm{c}}$ & $0,44 \pm 0,04^{\mathrm{d}}$ & $0,39 \pm 0,03^{\mathrm{d}}$ \\
\hline C17:1 & $0,27 \pm 0,02^{\mathrm{d}}$ & $0,35 \pm 0,01^{\mathrm{c}}$ & $0,43 \pm 0,02^{\mathrm{bc}}$ & $0,48 \pm 0,03^{\mathrm{b}}$ & $0,61 \pm 0,06^{\mathrm{a}}$ \\
\hline C18:0 & $1,82 \pm 0,04^{\mathrm{e}}$ & $2,18 \pm 0,04^{\mathrm{d}}$ & $2,39 \pm 0,04^{\mathrm{c}}$ & $2,54 \pm 0,06^{\mathrm{b}}$ & $2,73 \pm 0,06^{\mathrm{a}}$ \\
\hline C18:1 n9 & $21,44 \pm 0,61^{\mathrm{a}}$ & $19,65 \pm 0,47^{\mathrm{b}}$ & $18,30 \pm 0,22^{\mathrm{c}}$ & $17,10 \pm 0,11^{\mathrm{d}}$ & $14,18 \pm 0,34^{\mathrm{e}}$ \\
\hline C18:1n7 & $2,75 \pm 0,10^{\mathrm{a}}$ & $2,33 \pm 0,09^{\mathrm{b}}$ & $2,21 \pm 0,12^{\mathrm{bc}}$ & $2,04 \pm 0,03^{\text {cd }}$ & $1,89 \pm 0,09^{\mathrm{d}}$ \\
\hline C18:2 n6 & $11,77 \pm 0,47^{\mathrm{c}}$ & $12,12 \pm 0,13^{\mathrm{c}}$ & $12,47 \pm 0,03^{\mathrm{bc}}$ & $12,93 \pm 0,08^{\mathrm{b}}$ & $14,58 \pm 0,43^{\mathrm{a}}$ \\
\hline C18:3 n3 & $3,19 \pm 0,06^{\mathrm{e}}$ & $3,60 \pm 0,06^{\mathrm{d}}$ & $4,11 \pm 0,02^{\mathrm{c}}$ & $4,54 \pm 0,02^{\mathrm{b}}$ & $4,75 \pm 0,14^{\mathrm{a}}$ \\
\hline C20:0 & $2,57 \pm 0,04^{\mathrm{d}}$ & $2,85 \pm 0,05^{\mathrm{c}}$ & $2,95 \pm 0,04^{\mathrm{c}}$ & $3,08 \pm 0,03^{\mathrm{b}}$ & $3,52 \pm 0,04^{\mathrm{a}}$ \\
\hline C20:1 & $1,22 \pm 0,03^{\mathrm{a}}$ & $1,02 \pm 0,03^{\mathrm{b}}$ & $0,87 \pm 0,02^{\mathrm{c}}$ & $0,73 \pm 0,04^{\mathrm{d}}$ & $0,43 \pm 0,03^{\mathrm{e}}$ \\
\hline C20:2 & $0,89 \pm 0,09^{\mathrm{d}}$ & $1,15 \pm 0,02^{\mathrm{c}}$ & $1,28 \pm 0,03^{\mathrm{c}}$ & $1,45 \pm 0,02^{\mathrm{b}}$ & $1,64 \pm 0,06^{\mathrm{a}}$ \\
\hline C20:3n6 & $0,23 \pm 0,02^{\mathrm{d}}$ & $0,41 \pm 0,07^{\mathrm{c}}$ & $0,52 \pm 0,03^{\mathrm{c}}$ & $0,64 \pm 0,01^{\mathrm{b}}$ & $0,92 \pm 0,04^{\mathrm{a}}$ \\
\hline C20:4 n6 & $0,81 \pm 0,02^{\mathrm{a}}$ & $0,86 \pm 0,06^{\mathrm{a}}$ & $0,86 \pm 0,08^{\mathrm{a}}$ & $0,91 \pm 0,03^{\mathrm{a}}$ & $0,86 \pm 0,06^{\mathrm{a}}$ \\
\hline C20:5 n3 & $3,42 \pm 0,11^{\mathrm{d}}$ & $3,87 \pm 0,05^{\mathrm{c}}$ & $4,29 \pm 0,08^{\mathrm{b}}$ & $5,19 \pm 0,06^{\mathrm{a}}$ & $5,19 \pm 0,16^{\mathrm{a}}$ \\
\hline C22:1n9 & $0,43 \pm 0,07^{\mathrm{c}}$ & $0,88 \pm 0,81^{\mathrm{b}}$ & $0,94 \pm 0,07^{\mathrm{b}}$ & $1,23 \pm 0,02^{\mathrm{a}}$ & $1,31 \pm 0,02^{\mathrm{a}}$ \\
\hline C22:2 & $0,27 \pm 0,04^{\mathrm{d}}$ & $0,28 \pm 0,04^{\mathrm{d}}$ & $0,71 \pm 0,02^{\mathrm{c}}$ & $0,87 \pm 0,06^{\mathrm{b}}$ & $1,14 \pm 0,06^{\mathrm{a}}$ \\
\hline C23:0 & $0,32 \pm 0,04^{\mathrm{b}}$ & $0,32 \pm 0,01^{\mathrm{b}}$ & $0,35 \pm 0,05^{\mathrm{ab}}$ & $0,36 \pm 0,06^{\mathrm{ab}}$ & $0,46 \pm 0,06^{\mathrm{a}}$ \\
\hline C24:0 & $0,97 \pm 0,11^{\mathrm{c}}$ & $1,11 \pm 0,02^{\mathrm{c}}$ & $1,45 \pm 0,03^{\mathrm{b}}$ & $1,72 \pm 0,10^{\mathrm{a}}$ & $1,76 \pm 0,08^{\mathrm{a}}$ \\
\hline C22:6 n3 & $9,58 \pm 0,23^{\mathrm{d}}$ & $10,71 \pm 0,18^{c}$ & $11,28 \pm 0,06^{\mathrm{b}}$ & $11,75 \pm 0,19^{b}$ & $12,37 \pm 0,19^{\mathrm{a}}$ \\
\hline DYA & $24,88 \pm 0,23^{\mathrm{a}}$ & $23,81 \pm 0,22^{\mathrm{b}}$ & $23,14 \pm 0,04^{\mathrm{c}}$ & $22,87 \pm 0,12^{\mathrm{c}}$ & $23,18 \pm 0,09^{\mathrm{c}}$ \\
\hline TDYA & $27,43 \pm 0,25^{\mathrm{a}}$ & $25,25 \pm 0,27^{\mathrm{b}}$ & $23,69 \pm 0,15^{\mathrm{c}}$ & $22,36 \pm 0,02^{\mathrm{d}}$ & $18,98 \pm 0,31^{\mathrm{e}}$ \\
\hline ÇDYA & $30,15 \pm 0,45^{\mathrm{e}}$ & $33,00 \pm 0,07^{\mathrm{d}}$ & $35,52 \pm 0,07^{\mathrm{c}}$ & $38,28 \pm 0,04^{\mathrm{b}}$ & $41,45 \pm 0,29^{\mathrm{a}}$ \\
\hline
\end{tabular}

\section{Araştırma Sonuçları ve Tartışma}

Besleme periyodu sonrasında hasat edilen balıklarımızdan alınan kas örneklerinin yağ asidi profiline bakılmış ve sonuçlar Tablo 2'de sunulmuştur.

$\mathrm{Bu}$ araştırmada balıketinden alınan numunelerde toplam 24 adet yağ asidi tanımlanmıştır. Tanımlanabilen bu yağ asitlerinin 9 DYA'nın yaklaşık \%50'sini oluşturmuştur.

Özellikle ÇDYA ve TDYA'lerinin insan sağlığı ve gelişimi üzerinde yararlı ve koruyucu etkileri vardır. Yapılan birçok araştırmada yağ asitlerinin çoğu kanser gelişimini baskılamada ve tanesi doymuş (DYA), 7 tanesi tekli doymamış (TDYA) ve 8 tanesi ise çoklu doymamış yağ asitlerindendir (ÇDYA).

Balıketindeki DYA, yeme ilave edilen borik asit miktarı arttıkça artış göstermiş fakat $\% 0.05, \% 0.10$ ve $\% 0.20$ borik asit ilave edilen gruplar arasında istatiksel olarak fark oluşmamıştır. Araştırmamızda palmitik asit, hem borik asit ilaveli gruplarda hemde kontrol grubunda en baskın DYA olmuş ve toplam

kardiyovasküler hastalık riskini azaltmada güçlü bir rol oynadığ bildirilmiştir. Özellikle uzun zincirli n-3 serisi yağ asitlerinin ana kaynağı balıklardır. Sağlık bilinci yüksek tüketiciler hangi balığın hangi mevsimde hangi yağ asitlerince zengin olduğunu takip etmekte ve tüketimini buna göre şekillendirmektedir. Bu yüzden 
balıklarda yağ asitlerinin belirlenmesi oldukça önemli bir konudur.

Gökkuşağı alabalığının palmitik asit oranını \%15.98-18.41 arasında olduğu bildirilmiştir (Dernekbaşı ve ark., 2011). Başka bir araştırmada da teleostlarda palmitik asitin hemen hemen tüm balık dokularında baskın olduğu rapor edilmiştir (Aras ve ark., 2003).

Tekli doymamış yağ asitleri incelendiğinde kontrol grubunda $27,43 \pm 0,25$ olan toplam değerimiz borik asit ilavesi arttıkça düşüş göstermiş ve \% 0,20 borik asit ilaveli grupta $18,98 \pm 0,3$ 'e düşmüştür.

Araştırmada en baskın tekli doymamış yağ asidi oleik asit olmuştur. Bu sonuca benzer bir şekilde, Dernekbaşı ve ark. (2011) Gökkuşağı alabalığının en baskın tekli doymamış yağ asidini oleik asit ve palmitoleik asit olarak bildirmiştir. Balıklarda yumurta ve gonad gelişimi için ihtiyaç duyulan metabolik enerji TDYA'lardan sağlandığından balıketinde en çok depolanabilen yağ asitleri TDYA'lardır (Sargent, 1995).

Toplam DYA ve TDYA değerlerinin aksine borik asit ilaveli gruplarımızın toplam ÇDYA miktarlarında artış görülmüştür ve elde edilen değerlerimiz sırasıyla; $30.18,33.00,35.52,38.28$ ve 41.45 bulunmuştur.

İnsan sağlığı açısından önemli bir yere sahip olan EPA (20:5 $\omega-3 ; 3.42-5.19)$ ve $\operatorname{DHA}(22: 6 \omega-3 ; 9.58-12.37)$ miktarı borik asit ilaveli yemle beslenen gruplarda daha yüksek bulunmuştur. Afridi ve ark. (2019) yaptığı araştırmada bakırın rohu (Labeo rohita) ve mrigal'in (Cirrhinus mrigala) kas yağ asidi profilleri üzerindeki toksik etkilerini incelemişler. Araştırma sonucunda bakıra maruz bırakılan rohu ve mrigal'in EPA miktarlarında artış olduğunu bildirmiştir. Ayrıca rohu'un DHA miktarının azaldığını ve mrigal'in DHA miktarlarında artış olduğunu bildirmiştir.

Nil tilapiası üzerine yapılan bir araştırmada karaciğer ve solungaç dokularından alınan örneklerde phospholipid alt sınıflarının yağ asidi profiline deltametrinin toksik etkisi incelenmiştir. Araştırmada DYA ve TDYA'larda azalma görüldüğü ve ÇDYA miktarlarında ise artış olduğu rapor edilmiştir (Cengiz ve ark., 2017).

Balık yağı yerine bitkisel yağların gökkuşağı alabalığının büyüme performansı ve yağ asidi profili üzerindeki etkilerinin araştırıldığı başka bir araştırmada yem rasyonunun içeriğinin balığın yağ asidi profilini önemli ölçüde etkilediği bildirilmiştir (Yıldiz ve ark., 2018).

Balıkların yağ asidi profilindeki türler içindeki ve türler arasındaki varyasyon, balıkların beslendiği yemlerin rasyonlarındaki farklılıklardan kaynaklanmaktadır (Sargent ve ark., 1995; Ahigren ve ark., 1996 ). Bu araştırmada da balık yemine ilave edilen borik asit, gruplarımızın yağ asitlerinin farklılaşmasına sebep olmuştur.

\section{Sonuç}

Araştırma sonucunda; en yüksek DYA ve TDYA oranı kontrol gurubunda görülürken en düşük DYA ve TDYA oranı en fazla bor uygulanan grupta görülmüştür. Balık yemlerine ilave edilen bor mineralinin balıketinin ÇDYA oranlarında artış sağladığı görülmektedir. Alabalık yemine ilave edilen borun balıketinin toplam DYA ve TDYA oranında düşüşe, toplam ÇDYA oranında ise artışa sebep olduğu sonucuna varılmıştır.

\section{Kaynakça}

Acar, Ü., Kesbiç, O. S., İnanan, B. E., \& Yılmaz, S. (2019). Effects of dietary Bergamot (Citrus bergamia) peel oil on growth, haematology and immune response of European sea bass (Dicentrarchus labrax) juveniles. Aquaculture Research, 50(11), 3305-3312.

Acar, Ü., Kesbiç, O. S., Yılmaz, S., İnanan, B. E., ZemheriNavruz, F., Terzi, F., ... \& Parrino, V. (2021). Effects of Essential Oil Derived from the Bitter Orange (Citrus aurantium) on Growth Performance, Histology and Gene Expression Levels in Common Carp Juveniles (Cyprinus carpio). Animals, 11(5), 1431.

Afridi, A. J., Zuberi, A., Yousafzai, A. M., Kamran, M., \& Ullah, S. (2019). Hemp (Marijuana) reverted Copper-induced toxic effects on the essential fatty acid profile of Labeo rohita and Cirrhinus mrigala. Molecular biology reports, 46(1), 391401.

Ahigren, G., Sonesten, L., Boberg, M., \& Gustafsson, L. B. (1996). Fattv acid content of some freshwater fish in lakes of different trophic levels-a bottom-up effect?. Ecology of Freshwater Fish, 5(1), 15-27.

Aras N.M., Haliloğlu H.İ., Bayır A., Atamanalp M. and A.N. Sirkecioğlu, 2003. Karasu havzası yeşildere çayı olgun dere alabalıkları (Salmo trutta macrostigma, Dumeril, 1858) 'nda farklı dokuların yă asidi kompozisyonlarının karşılaştırılması. Turkish J. Vet. Anim. Sci., 27:887-892.

Ardó L, Yin G, Xu P, Váradi L, Szigeti G, Jeney Z, Jeney G. 2008. Chinese herbs (Astragalus membranaceus and Lonicera japonica) and boron enhance the non-specific immune response of Nile tilapia (Oreochromis niloticus) and resistance against Aeromonas hydrophila. Aquaculture. 275:26-33.

Cengiz, E. I., Bayar, A. S., Kızmaz, V., Başhan, M., \& Satar, A. (2017). Acute toxicity of deltamethrin on the fatty acid composition of phospholipid classes in liver and gill tissues of Nile tilapia. International Journal of Environmental Research, 11(3), 377-385.

Czesny S, Dabrowski K (1998) The effect of egg fatty acid concentrations on embryo viability in wild and domesticated walleye (Stizostedion vitreum). Aquat Living Resour 11(6):371-378. https://doi.org/10.1016 /S09907440(99)80002-3

Dernekbaşi, S., Karayücel, İ., \& Öksüz, A. (2011). Effect of dietary canola oil level on fatty acid composition of rainbow trout (Oncorhynchus mykiss L.).

Dikel, S. (2021). Ilıman İklim Balıkları Yetiştiriciliği. Editör, Suat DİKEL. Akademisyen kitabevi, ISBN: 978-625-7275-63-7, DOI: 10.37609/akya.559.

Folch J, Lees M, Stanley GS (1957) A simple method for the isolation and purification of total lipides from animal tissues. J Biol Chem. 226(1):497-509.

Işik O, Sarihan E, Kuşvuran E, Gül Ö, Erbatur O (1999) Comparison of the fatty acid composition of the freshwater fish larvae Tilapia zillii, the rotifer Brachionus calyciflorus, and the microalgae Scenedesmus abundans, Monoraphidium minitum and Chlorella vulgaris in the algae-rotifer-fish larvae food chains. Aquaculture 174(3-4):299-311. 
İnanan, B. E., Acar, Ü., \& İnanan, T. (2021). Effects of dietary Ferula elaeochytris root powder concentrations on haematology, serum biochemical parameters, spermatozoa parameters, and oxidative status in tissues of males goldfish (Carassius auratus). Aquaculture, 544, 737087.

İnanan, B. E., Acar, Ü., (2019). Evaluation of Sugar Beet Leave Extracts in Goldfish (Carassius auratus) Diets: Effects on Blood and Semen Parameters. Acta Aquatica Turcica, 15(4), 458-468.

Metcalfe LD, Schmitz AA (1961) The rapid preparation of fatty acid esters for gas chromatographic analysis. Anal Chem 33(3):363-364. https://doi.org/10.1021/ac60171a016.

Öz, M. (2018). Effects of garlic (Allium sativum) supplemented fish diet on sensory, chemical and microbiological properties of rainbow trout during storage at- $18 \mathrm{C}$. LWT, 92, 155-160.

Öz, M., Dikel, S., \& Durmus, M. (2018a). Effect of black cumin oil (Nigella sativa) on the growth performance, body composition and fatty acid profile of rainbow trout (Oncorhynchus mykiss). Iranian Journal of Fisheries Sciences, 17(4), 713-724.

Öz, M., Dikel, S., İnanan, B. E., Karaşahin, T., Durmuş, M. U. Y., \& Uçar, Y. (2017). Borik asidin gökkuşağ 1 alabalığ (Oncorhynchus mykiss)'nın hepatosomatik ve viserosomatik indeks değerleri üzerine etkileri. Journal of Advances in VetBio Science and Techniques JAVST, 2(1), 6-10.

Öz, M., Inanan, B. E., \& Dikel, S. (2018b). Effect of boric acid in rainbow trout (Oncorhynchus mykiss) growth performance. Journal of Applied Animal Research, 46(1), 990-993.

Öz, M., Karașahin, T., Aksoy, N. H., Inanan, B. E., \& DIKEL, S. (2020b). Harmful effects of dietary supplementation of boron on blood parameters of Rainbow Trout (Oncorhynchus mykiss). Journal of the Hellenic Veterinary Medical Society, 71(2), 2227-2234.

Öz, M., Tatil, T., \& Dikel, S. (2021). Effects of boric acid on the growth performance and nutritional content of rainbow trout (Oncorhynchus mykiss). Chemosphere, 129895.

Öz, M., Üstüner, E. (2021). Sazan (Cyprinus carpio Linnaeus, 1758) Yetiştiriciliği. Ilıman İklim Balıkları Yetiştiriciliği. Editör, Suat DİKEL. Akademisyen kitabevi, ISBN: 978-6257275-63-7, DOI: 10.37609/akya.559.

Öz, M., Yavuz, O., \& Bolukbas, F. (2020a). Histopathology changes in the rainbow trout (Onchorhyncus mykiss) consuming boric acid supplemented fish fodder. Journal of Trace Elements in Medicine and Biology, 62, 126581.

Sargent, J. R. (1995). Origins and function of eggs lipids: Nutritional implication. Broodstock management and egg and larval quality, 353-372.

Sargent, J. R., Bell, J. G., Bell, M. V., Henderson, R. J., \& Tocher, D. R. (1995). Requirement criteria for essential fatty acids. Journal of applied Ichthyology, 11(3/4), 183-198.

Uçak, I., Oz, M., \& Maqsood, S. (2019). Products based on omega-3 polyunsaturated fatty acids and health effects. The Role of Alternative and Innovative Food Ingredients and Products in Consumer Wellness; Elsevier: Amsterdam, The Netherlands.

Yıldız, M., Eroldoğan, T. O., Ofori-Mensah, S., Engin, K., \& Baltac1, M. A. (2018). The effects of fish oil replacement by vegetable oils on growth performance and fatty acid profile of rainbow trout: Re-feeding with fish oil finishing diet improved the fatty acid composition. Aquaculture, 488, 123 133. 